\title{
Role of patriotic education of adolescents in present-day green society
}

\author{
Elizaveta Lunkova ${ }^{1, *}$, Victor Gorelik ${ }^{1}$, Tatiana Khorosheva ${ }^{1}$, Igor Demeshev ${ }^{1}$, \\ Elena Voronkova ${ }^{1}$, and Natalia Ponomareva ${ }^{1}$ \\ ${ }^{1}$ Togliatti State University, Togliatti, Russia
}

\begin{abstract}
The paper discusses the purpose of formation of spiritual and moral values in young generation when taking martial arts classes, including karate. It is noted that patriotic upbringing should play an integral role in physical development and fitness of the athletes. The paper explains the meaning of socially important cultural values in martial arts practice and looks into spiritual and moral development to prevent breaking social norms of conduct among adolescents. Person-centred approach is of vital importance for spiritual and moral education, since it draws on the athletes' motivation. The person-centred approach emphasises the autonomy, emotional component, moral and ethical development of the trainees. A particular focus is given to the problem of moral guidance and the lack of patriotism among the students of educational institutions. Mass media fail to pay due attention to the patriotic upbringing what results in the absence of generation-bridging and weaker patriotic feelings among children. There are not many schools that run military-patriotic classes. Hence, spiritual and moral education works for effective development of patriotism among martial arts athletes.
\end{abstract}

\section{Introduction}

The popularity of martial arts is growing with each year passing. They attract nowadays children with a variety of directions and techniques. A number of factors work for their popularity. One of the main advantages is physical fitness of the trainees. Regular exercises promote harmonious development of personality and physical qualities as well as normalising the work of children's body [1].

The word «art» is not least important, which instils a more profound meaning than mere physical exercises. Most martial arts have centuries of history and each has its own philosophy. The role of patriotic upbringing in the practice of martial arts should be noted [2].

\footnotetext{
${ }^{*}$ Corresponding author: lecgoy@list.ru
} 


\section{Problem statement}

The problem of spiritual and moral education among the young generation is a well-known issue for nowadays society. The term «morals» is a part of a certain code of conduct that guides a person throughout one's life and communicates one's attitude to the society and motherland [3].

According to the data of statistical indicators of spiritual and moral values formation, standard methods for moral education of nowadays adolescents are insufficient. A personcentred approach is needed that would consider the interests of children and adolescents [4].

\section{Research questions}

One of the best drivers of spiritual and moral education is culture. However, current generation of children shows a strong interest to its physical aspect. The role of the physical education is to bring balance physical and moral strengths, to promote universal values like health, fitness and mental well-being [5].

Karate significantly improves coordination abilities since it practises the range of activities that may be expected to occur or happen spontaneously. This enables children to be creative, react quickly, be able to focus and refocus [6].

In the view of the above, we came to the conclusion that it is necessary to instil spiritual and moral values in adolescents through martial arts.

Our purpose of the study is to study the influence of spiritual and moral education when practising martial arts.

\section{Research methods}

1. To analyse the formation level of spiritual and moral values among young generation.

2. To develop a set of measures to form spiritual and moral values among trainees.

3. To assess the efficiency of the applied measures.

In this study, the method of analysis of literary sources, pedagogical observation of students, questionnaires and the method of mathematical processing were used. In order to determine the initial level of formation of spiritual and moral values among trainees, the method of M.I. Shilova was applied. The chosen methodology covers five basic indicators for moral development:

- Self-discipline;

- Attitude to intellectual work;

- Attitude to the society, patriotism;

- Attitude to intellectual work;

- Attitude to people.

The study involved students of the sixth grades «A» and «B» at the age of 11-12 years. Grade «A» made up an experimental group (EG), and pupils of grade «B» entered a control group (CG). There were held military-patriotic activities, conversations as well as meetings with famous athletes and workers of culture in the experimental group. In addition to the regular physical activity, conversations and lectures on the martial arts etiquette, upbringing of spirituality and morality were held with the students in EG. Karate classes were held twice a week with children from EG and CG. There were no patriotic education classes in CG.

At the beginning of the study, children from both groups were tested by M.I.Shilova method. The following results were obtained. 


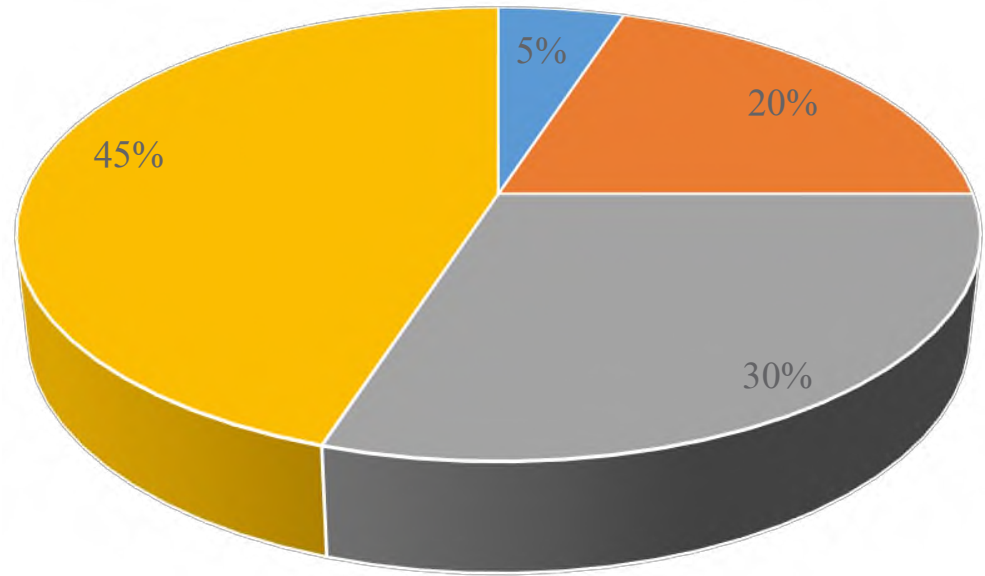

- High level $\|$ Average level $\square$ Level below average $\square$ Low level

Fig. 1. The level of moral development of EG at the beginning of the study.

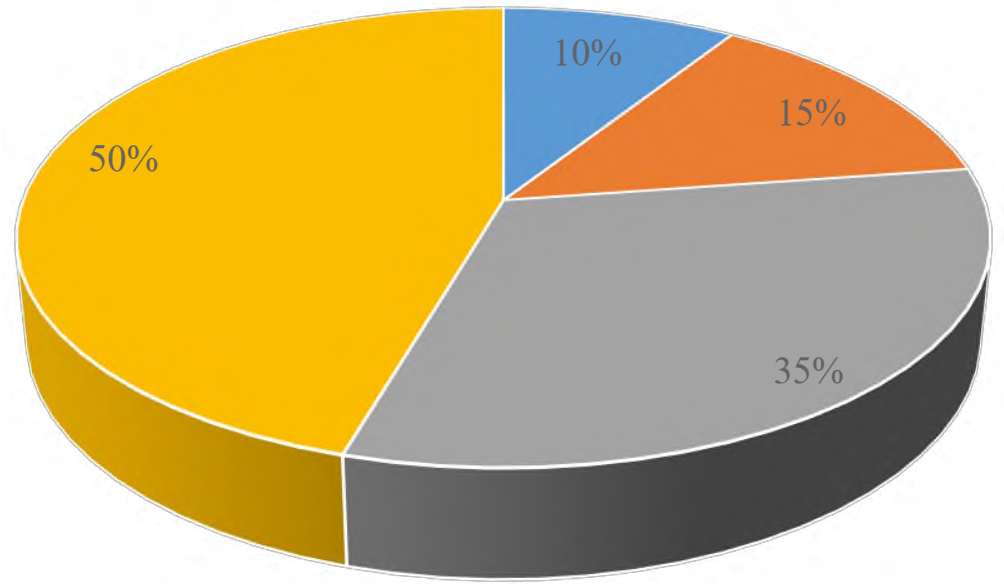

- High level $\backsim$ Average level $\backsim$ Level below average $\backsim$ Low level

Fig. 2. The level of moral development of $\mathrm{CG}$ at the beginning of the study. 
Figures 1 and 2 display that both groups have a low level of formation of moral values. According to the diagram, percentage of children with high level of moral development is critically small.

After completion of the whole set of educational measures and the karate course, both groups were tested by the M.I. Shilova method.

And the following results were obtained.

The obtained data show that the level of moral education in EG increased significantly, and it did not in CG. There was an increase in self-discipline, intellectual work, patriotism; improved attitude towards people; higher interest in physical work. The high level increases by $35 \%$, the average level rises by $40 \%$, the level below average decreases by $40 \%$, and the low level decreases by $50 \%$ in EG. These data indicate that the proposed set of measures for the patriotic education of young generation in EG allowed increasing the level of moral development.

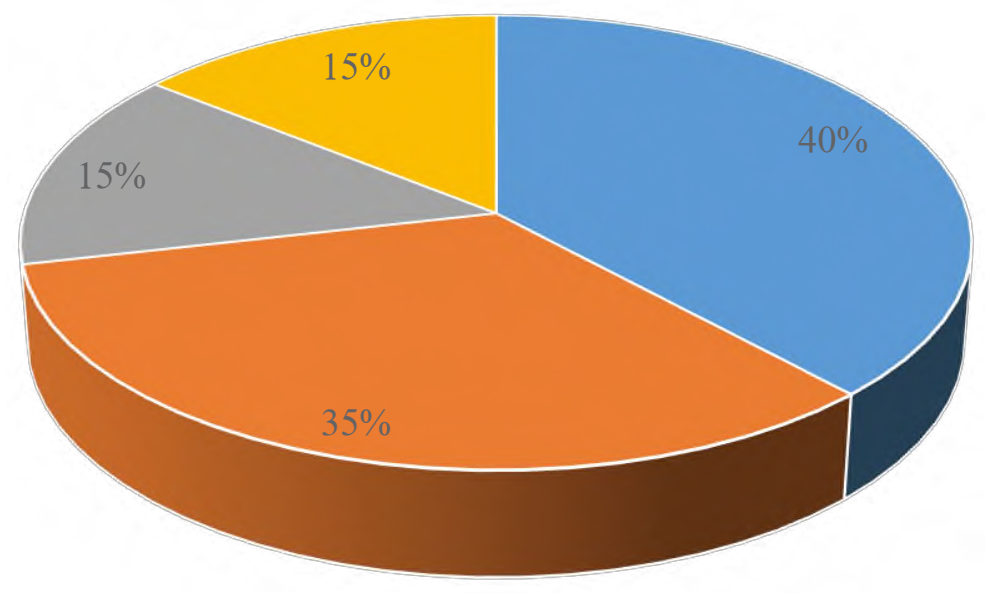

- High level $\square$ Average level $\square$ Level below average $\square$ Low level

Fig. 3. The level of moral development of EG at the end of the study. 


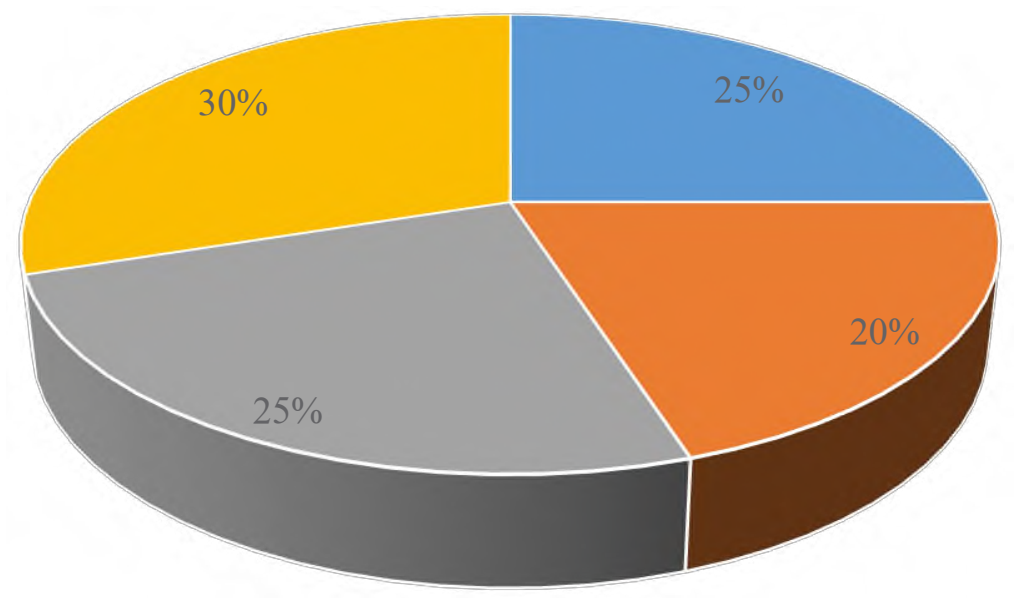

- High level $\quad$ Average level $\quad$ Level below agerage $\quad$ Low level

Fig. 4. The level of moral development of CG at the end of the study.

\section{Results}

The results of the study show that the planned activities for spiritual and moral education of pupils are not enough. It is necessary to tap into lectures, discussions as well as meeting with renowned athletes, actors, artists, musicians, veterans of World War II and other combat zones in order to efficiently instil patriotic feelings. Statistics obtained through questionnaires proved the effectiveness of the education of spiritual and moral qualities of young generation. This facilitates successful martial arts training and socially significant behaviour in modern society.

\section{Conclusion}

1. Both groups were surveyed at the beginning of the study by M.I. Shilova method. The obtained results showed that the moral development of both EG and CG was approximately at the same level and had no significant differences.

2. A set of measure, aimed at instilling moral conduct into six-graders, made it possible to improve the level of spiritual and moral education in EG in comparison to CG.

\section{References}

1. A.A. Golovnin, Upbrining of adolescents through Kyokushin karate: healthimproving, mental, spiritual and moral components of the training. The Lesgaft University transactions 5, 135-231 (2018)

2. A.A. Golovnin, A.N. Savchuk, Development of physical culture among pupils through martial arts (on the example of kyokushin karate). Human. Sport. Medicine. 39, 177182 (2011) 
3. A.P. Kozlov, The beginning of spread and development of oriental martial arts in Europe and the world. Vestnik of TSU 1, 67-72 (2014)

4. A.V. Safoshin, V.I. Strelkov, V.O. Agafonova, On the question of features of development of personality in martial arts. Issues of the modern education. 6, 64-71 (2016)

5. A.V. Safoshin, Social-pedagogical nature of oriental martial arts philosophy: person-centred approach. Science and school 4, 9-204 (2015)

6. Sh.Yu. Shikhshabekov, G.K. Magomedov, Sh. Z. Ibragimova, Role of oriental martial arts and wushu in forming a harmoniously developed personality // Vestnik of SPI. 2 (18), 231-234 (2016) 